\title{
Messages from the minefield
}

To attempt to comment on salary levels of scientists is to venture into a minefield. Off in various directions are snares such as historical precedents, parities between government, universities and industry, relations to the cost of living index, and rivalries, even jealousies, between different professions. The appearance of the latest remuneration survey of the Institute of Physics (Physics Bulletin, April 1976), however, presents a good opportunity to review the way that physicists are paid. With severe and externally imposed restraint on increases in income this year, and probably next, now is also a good time to look at a scene relatively uncluttered by salary negotiations.

The Institute of Physics has carried out salary surveys for more than 20 years, and although there has been considerable variability in the method of reporting, it is possible to see general trends. The table shows the median salary for Fellows of the Institute (the top grade; roughly $20 \%$ of the total membership). Where this figure has not theless, two points can be made: that the rewards of being a scientist grew steadily until the mid-1960s, and that since then the rewards have barely held their own.

For the past year or two we have all been rediscovering industry, relearning that the country cannot function without a productive industrial sector, attempting to help industry by increasing university links, and so on. But figures from the survey show how unattractive industrial salaries look in comparison with government and university pay. In 1974 the median salaries for all the institute's membership (not just Fellows) were $£ 3,400$ in industry, $£ 4,420$ in university, $£ 3,500$ in central government. By 1976 industry and university medians had moved roughly with the cost of living to $£ 5,000$ and $£ 6,300$, while central government had risen all of $70 \%$ to $£ 6,000$.

A cross-check on these last figures can be found in the most recent remuneration survey of the Institute of Electrical Engineers for January 1976. This confirms that

\begin{tabular}{lrrrrrrrrr}
\hline Date of survey & 1951 & 1953 & 1956 & 1960 & 1964 & 1967 & 1971 & 1974 & 1976 \\
Median salary of Fellows (£) & 1,400 & 1,550 & 1,950 & 2,350 & 3,300 & 3,600 & 4,620 & 5,850 & 8,260 \\
Median in 1974 (£) & 3,800 & 3,900 & 4,300 & 4,800 & 6,000 & 5,800 & 6,000 & 5,850 & 5,550 \\
\hline
\end{tabular}

been explicitly published, an attempt has been made to extract it from the statistics available. The median for the top grade may not be the ideal pointer, but it is the only one easily available, and nothing seen in other data gives the impression that it is out of line with other trends.

The table also contains salaries converted to January 1974 levels by use of the cost of living index. Purists will no doubt shudder at the misuse of statistics: no allowance has been made for the progressive nature of income tax, and the cost of living index is only a helpful guide to those whose salaries do not differ too much from the national average. As a result the contrast between the 1950s and the 1970 s is probably not as marked as it seems. Never- median salaries in central government, the nationalised industries and universities are more than $£ 1,000$ higher than those in industry. No doubt there can be bickering over fringe benefits, security of tenure, relative qualifications, pension schemes, and so on, but the message is clear enough: the sector of the economy that is looked upon to solve our present economic woes cannot match the salary rewards that are available elsewhere; and with pay restraint this balance is unlikely to be redressed for some years. Historically, salaries in the three spheres of government, university, and industry have never got so far out of line as this. Does the government realise the consequences, including that of damping mobility out of the public sector?

\section{Concorde's circadian conquest}

"Businessmen interviewed as they disembarked at Heathrow Airport recently after a British Airways Concorde flight from Bahrain had one thing in commonthey felt alert without any suggestion of "jet lag'."

So runs a recent British Airways advertisement for Transatlantic Concorde. The operation is about as meaningful as being assured by the departing clientele of a pub at closing time that they are not suffering from a hangover.

There is no precise definition of what jet lag is, but if you gave those businessmen at Heathrow time to think for a bit they would probably perceive through the haze of Chateau Brane Cantenac ' 70 that they couldn't know whether they were jet lagged until they had found out whether their internal clocks were waking them up at the witching hour of $3 \mathrm{AM}$ the following morning. And that will happen, Concorde or 707. But no doubt in their haste to get back to their office they would settle for a definition of jet lag as the way they felt on emerging from the plane. Besides, you've got to justify the elevated price by something besides the smoked salmon and peaches in kirsch.

Now all this is as harmless as claiming that a certain dogfood prolongs active life or a certain sauce is $99.46 \%$ pure. But wait until the businessmen are being enticed to fly to a day's work in New York and to return to London the same day. British Airways won't be interviewing them at Heathrow about jet lag, because they'll be travel-weary. They'll be rung up the following morning in their office and asked did they wake at an unearthly hour. Of course they didn't-Concorde cuts jet lag either way. 